\title{
Energy Effective Polyester Production
}

\author{
Budin, R. \& MiHELIC-BogdANIC, A.
}

Abstract: Synthetic fibre industry i.e. polyester production is an energy intensive process which unit operations use fuel directly and transformed forms of primary energy like heat and electricity. Important progress could be achieved by the development and the application of the several successful options directed to reducing energy consumption. Therefore the aim of presented analysis is to suggest one of the possibilities for energy conservation implementing combined heat and power production (CHP). The proposed cogeneration process compared with the conventional system results with absolute efficiency increasing of 35,5\%. With regard to whole energy demand i.e. fuels directly, heat and electrical energy savings in primary energy source is about $65 \%$.

Key words: polyester, energy consumption, cogeneration, savings
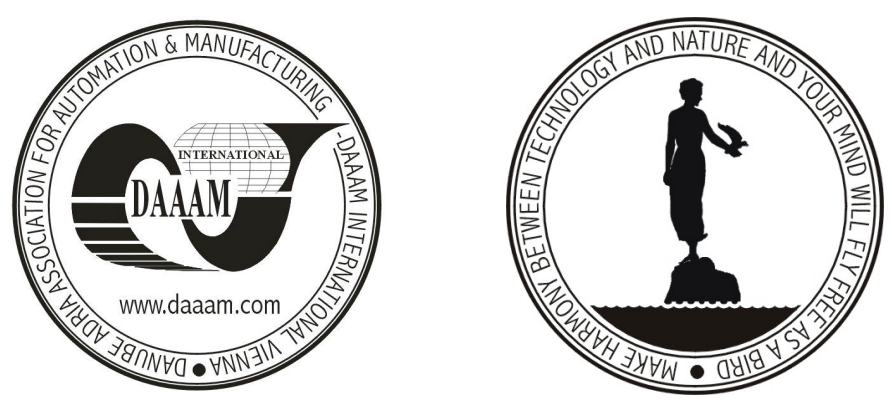

Authors' data: Prof. Dr. Budin R.[ajka]*, Prof. Dr. Mihelic-Bogdanic A.[1ka]**, *Faculty of chemical engineering and technology Zagreb, Croatia, **Faculty of textile technology, Zagreb, Croatia, rbudin@marie.fkit.hr, amihel@marie. fkit.hr

This Publication has to be referred as: Budin, R. \& Mihelic-Bogdanic, A. (2006). Energy Effective Polyester Production, Chapter 09 in DAAAM International Scientific Book 2006, B. Katalinic (Ed.), Published by DAAAM International, ISBN 3-901509-47-X, ISSN 1726-9687, Vienna, Austria

DOI: $10.2507 /$ daaam.scibook.2006.09 